\title{
The first two CABG Surgeries in Nepal
}

\section{Dr. D. P. Pokharel, Dr. Subarna Tuladhar*}

The cardiothoracic and vascular surgery unit of Bir Hospital made a landmark in the history of Nepalese surgery by performing two open heart coronary artery bypass graft surgeries under the leadership of Dr. D. P. Pokharel and an entirely Nepali team on $2057 / 3 / 4$ an 2057/3/7.

The case summary of the two patients are presented as follows:

\section{1st Case}

68 year female, a housewife, presenting with a history of unstable angina on 2055/8/8. She was admitted in Bir Hospital ICU for 7 days.

Past history : Cholecystectomy 4 years ago

Diabetes mellitus diagnosed 2 years ago on dietary control

Personalhistory: Nonsmoker

Non alcoholic

Drug history : Lisinopril $5 \mathrm{mg} O D$

Isosorbide $5 \mathrm{mg}$ OD

Diltiazem $10 \mathrm{mg}$ OD

Aspirin $50 \mathrm{mg} O D$

Allergic history : none

Investigation:

Angiogram done in Delhi: Left circumflex 95\% distal stenosis.

Echocardiogram: ejection fraction $69 \%$

PFT: FEV1 $1440 \mathrm{~mL}$, FVC: $1700 \mathrm{~mL}$

TMT: stress test positive

ECG: T wave inversion in III and a VF

\section{On examination:}

Obese, Well nourished

Chest : VBS and CVS: SIS2MO

All preop investigation were WNL

CABG was one on $2057 / 3 / 4$

Left saphenous vein was grafted to the left circumflex artery 
Pacing wires were places in situ as well

Post operative: uneventful recovery. Closely monitored with regular ABG and electrolyte measurement and X-ray was done immediate post-op, 1st, 2nd and 5th post-op day.

There was some would infection, which is being dressed daily and blood sugar is closely monitored. Wound is healing well.

\section{2nd case:}

55 year male, a driver, presented with pain in lower half of chest on 2056/8/24. This was associated with nausea and sweating. He was diagnosed as anteroseptal MI and was treated accordingly in Norvic Heart Command Centre for 6 days. He again had pain in the left shoulder and arm after 10 days and went to TUTH again which was diagnosed as Class II angina. He was regularly followed up in Norvic and was advised to undergo coronary angiogram.

No other significant past history. No history of DM or HTN.

Smoker 4 day for the last 15 years and social drinker.

No known allergic history.

Drug history: Atenolol 25mg OD

Lisinopril $5 \mathrm{mg}$ OD

Caspy 100 mg OD

On examination:

No significant findings in general and systemic examination.

\section{Investigation:}

QS in VI-V3. Poor R progression in V1-V2. ST elevation in V1-V3. Anteroseptal MI with left axis deviation.

Angiogram done in Calcutta on 25 Feb, 2000:

Single vessel coronary artery disease involving proximal LAD ad ectatic post stenotic segment. Global LV systolic function is normal. 
Echocardiogram : 30 Nov 1999

Akinetic LV apex. LVEF 40-45\%. Hypokinetic mid segment of IVS and anterior wall.

PFT: FEV12240mL

FEV1\% 83.2\% mild restrictive ventilation

FVC : 2629

Patient was operated on $2057 / 3 / 7$

LIMA was anatomosed to LAD

Pacing wires were placed in situ

Post operatively there was acute gastric dilatation, which was relieved with NG tube. Leg and chest drains were removed on 1 st post op day.

The arterial line was removed on the 2 nd post op day. The BP then subsequently fell to $70 / 50 \mathrm{mmHg}$. Dobutamine and adrenaline was started and slowly captopril $6.25 \mathrm{mg}$ TDS was introduced. Captopril was gradually increased to $18.75 \mathrm{mg}$ TDS over a few days whiledobutamine and adrenaline was gradually decreased. Patient also had episodes of bronchospasms for a few days, which was treated with salbutamol nebulizer and steam. He then made a good recovery. Some wound soakage was noted after 7 days, which is being dressed daily, and wound is healing well.

* CTVS unit Bir Hospital 